\title{
Effects of Chitosan on Soluble Sugar Content in Prunus davidiana Seedlings
}

\author{
Jing Sun ${ }^{1}$, Aihui Li², Qianhe Jing ${ }^{2}$, Yingying Huang ${ }^{2}$, Jiaxi Han² and Lijin Lin ${ }^{1 *}$ \\ ${ }^{1}$ Institute of Pomology and Olericulture, Sichuan Agricultural University, Chengdu, Sichuan, 611130, China \\ ${ }^{2}$ College of Horticulture, Sichuan Agricultural University, Chengdu, Sichuan, 611130, China
}

\begin{abstract}
A pot experiment was conducted to study the effects of different concentrations of chitosan solutions $(0,1,2,4,6 \mathrm{~g} / \mathrm{L})$ on soluble sugar content in Prunus davidiana seedlings. The result showed that there was no significant difference of the soluble sugar content in roots, stems, leaves and shoot in $P$. davidiana seedlings between at $1 \mathrm{~g} / \mathrm{L}$ concentration and the control. All concentration treatments were reduced the soluble sugar content in roots and stems of $P$. davidiana seedlings compared with the control. On the contrary, all concentration treatments were improved the soluble sugar content in leaves and shoot of $P$. davidiana seedlings compared with the control and the concentration treatment of $2 \mathrm{~g} / \mathrm{L}$ and $4 \mathrm{~g} / \mathrm{L}$ was at a higher level. All concentration treatments were improved the content in relative conductivity of blade in $P$. davidiana seedlings and the concentration treatment of $4 \mathrm{~g} / \mathrm{L}$ was at a higher level. On the contrary, all concentration treatments were reduced the content in soil conductivity. Therefore, the chitosan solutions concentration of $2 \mathrm{~g} / \mathrm{L}$ and $4 \mathrm{~g} / \mathrm{L}$ concentration was beneficial to soluble sugar content in $P$. davidiana seedlings. On the contrary, high concentration of chitosan solutions was not good for soluble sugar content.
\end{abstract}

\section{Introduction}

Chitosan is a natural nitrogen-containing polysaccharide bioactive substance, which is the sixth essential life factor besides sugar, protein, fat, cellulose and minerals [1]. Many studies have shown that chitosan has great potential in promoting plant growth, increasing yield and improving quality. Chitosan can be used as crop growth regulator to enhance crop resistance, and promote seed germination, growth and development of crops such as soybeans, corn and wheat, and increase crop yields [2-4]. Many studies have shown that the effect of chitosan on seedling growth is reflected in low concentration promoting growth and high concentration inhibiting growth [5]. The study showes that the wet weight, dry weight, bud length and root length of radish seedlings increase with the increase of concentration in the range of $0 \%-0.25 \%$ chitosan, and the growth of these seedlings decrease when the concentration exceeded [6]. The study also showes that low concentration of chitosan can promote the growth of cucumber seedlings, while high concentration can inhibit the growth of cucumber seedlings [7]. Chitosan can also enhance the metabolism of sugars in seedlings, and enhance the fixation and synthesis of chlorophyll to sugars. The study showed that the soluble sugar content in seedlings increased with the increase of chitosan concentration in the range of $0 \%$ $0.8 \%$. When the concentration exceeded $0.8 \%$, the soluble sugar content in seedlings began to decrease again [8]. Thus, spraying chitosan requires an appropriate concentration. Therefore, this study investigated the effects of different concentrations of chitosan $(0,2,4,6,8 \mathrm{~g} / \mathrm{L})$ on soluble sugar content in Prunus davidiana seedlings then to screen out the optimum concentration that can promote growth of $P$. davidiana seedlings.

\section{Materials and methods}

\section{$2.1 \quad$ Materials}

$P$. davidiana seeds were purchased from a market in Chengdu, Sichuan, China. Non-polluted soil was collected from the Chengdu campus of Sichuan Agricultural University $\left(30^{\circ} 42^{\prime} \mathrm{N}, 103^{\circ} 51^{\prime} \mathrm{E}\right)$ in Chengdu, Sichuan, China. The basic soil properties were as follows: $\mathrm{pH}, 7.71$; organic matter content, $15.29 \mathrm{~g} / \mathrm{kg}$; alkaline nitrogen content, $87.99 \mathrm{mg} / \mathrm{kg}$; available phosphorus content, $55.77 \mathrm{mg} / \mathrm{kg}$; and available potassium content, $41.96 \mathrm{mg} / \mathrm{kg}$. The basic physical and chemical properties of the soil were based on references [9].

\subsection{Experimental design}

The Experiment was conducted in a greenhouse at the Chengdu campus of Sichuan Agricultural University from April to July 2019. In April 2019, P. davidiana seeds were sown in perlite and watered every 3 days. The germinated seeds were irrigated with Hoagland nutrient solution every 3 days until the seedlings reached a height of $10 \mathrm{~cm}$ (with about seven true leaves). Four uniformly

$\overline{* \text { Corresponding author's e-mail: 1lj800924@qq.com }}$ 
growing seedlings were transplanted to a pot $[15 \mathrm{~cm}$ (height) $\times 18 \mathrm{~cm}$ (diameter)] containing $3.0 \mathrm{~kg}$ soil. The soil moisture content was maintained at $80 \%$ of field capacity. At 7 days after transplanting, the leaves of $P$. davidiana seedlings were sprayed with chitosan solutions $(0,2,4,6$, or $8 \mathrm{~g} / \mathrm{L})$ until water droplets formed on the foliar surface, without dripping. Each treatment was repeated three times. At 1 month after the chitosan treatments, the upper mature leaves of $P$. davidiana seedlings were collected to determine the relative conductivity of blades by Conductivity Analyzer. And the roots, stem, and leaves of each plant were separately harvested, washed with tap water, and rinsed three times with deionized water. The plant materials were blanched at $110{ }^{\circ} \mathrm{C}$ for $15 \mathrm{~min}$, dried at $75{ }^{\circ} \mathrm{C}$ until reaching a constant weight, and weighed and crushed, which was used to determine the soluble sugar content in various parts of $P$. davidiana seedlings [10]. The soil in pots were air-dried and ground into a powder (soil particle diameter $<1 \mathrm{~mm}$ ) to determine the soil conductivity and the soil conductivity was measured with a 1:5 (w/v) suspension of soil and deionized water by Conductivity Analyzer.

\subsection{Statistical analyses}

Statistical analysis was carried out by using SPSS 18.0 statistical software. The data were analyzed by one-way
ANOVA, with the least significant difference at the 5\% confidence level.

\section{Results and Discussion}

\subsection{Soluble sugar content in $P$. davidiana seedlings}

There was no significant difference of the soluble sugar content in roots, stems, leaves and shoot in $P$. davidiana seedlings between at $1 \mathrm{~g} / \mathrm{L}$ concentration and the control. All concentration treatments of $P$. davidiana seedlings decreased the soluble sugar content in roots and stems compare with the control (Table 1). The soluble sugar content in roots decreased by $9.69 \%, 17.53 \%$ and $24 \%$ at $2 \mathrm{~g} / \mathrm{L}, 4 \mathrm{~g} / \mathrm{L}$ and $6 \mathrm{~g} / \mathrm{L}$ compared with the control, respectively. The soluble sugar content in stems decreased by $6.83 \%, 16.47 \%$ and $28.38 \%$ at $2 \mathrm{~g} / \mathrm{L}, 4 \mathrm{~g} / \mathrm{L}$ and $6 \mathrm{~g} / \mathrm{L}$ compared with the control, respectively. The soluble sugar content in leaves and shoot of $P$. davidiana seedlings of all concentration treatments was higher than the control except at $6 \mathrm{~g} / \mathrm{L}$. The soluble sugar content in leaves increased by $8.92 \%, 12.09 \%$ and $5.14 \%$ at $2 \mathrm{~g} / \mathrm{L}$, $4 \mathrm{~g} / \mathrm{L}$ and $6 \mathrm{~g} / \mathrm{L}$ compared with the control, respectively. The soluble sugar content in shoot of all concentration treatments increased by $5.72 \%$ and $5.54 \%$ at $2 \mathrm{~g} / \mathrm{L}$ and 4 $\mathrm{g} / \mathrm{L}$ compared with the control, respectively.

Table 1. Soluble sugar content in $P$. davidiana seedlings

\begin{tabular}{ccccc}
\hline $\begin{array}{c}\text { Treatments } \\
(\mathrm{g} / \mathrm{L})\end{array}$ & $\begin{array}{c}\text { Roots } \\
(\mathrm{mg} / \mathrm{g})\end{array}$ & $\begin{array}{c}\text { Stems } \\
(\mathrm{mg} / \mathrm{g})\end{array}$ & $\begin{array}{c}\text { Leaves } \\
(\mathrm{mg} / \mathrm{g})\end{array}$ & $\begin{array}{c}\text { Shoot } \\
(\mathrm{mg} / \mathrm{g})\end{array}$ \\
\hline 0 & $74.79 \pm 1.040 \mathrm{a}$ & $36.19 \pm 1.236 \mathrm{a}$ & $98.38 \pm 1.91 \mathrm{~d}$ & $71.70 \pm 1.62 \mathrm{~b}$ \\
1 & $72.76 \pm 1.379 \mathrm{a}$ & $35.03 \pm 0.521 \mathrm{ab}$ & $101.91 \pm 2.66 \mathrm{~cd}$ & $72.93 \pm 1.73 \mathrm{ab}$ \\
2 & $67.56 \pm 0.709 \mathrm{~b}$ & $33.72 \pm 0.954 \mathrm{~b}$ & $107.16 \pm 1.87 \mathrm{ab}$ & $75.80 \pm 1.48 \mathrm{a}$ \\
4 & $61.68 \pm 1.872 \mathrm{c}$ & $30.23 \pm 0.090 \mathrm{c}$ & $110.27 \pm 0.87 \mathrm{a}$ & $75.61 \pm 0.53 \mathrm{a}$ \\
6 & $56.84 \pm 0.132 \mathrm{~d}$ & $25.92 \pm 0.926 \mathrm{~d}$ & $103.44 \pm 0.86 \mathrm{bc}$ & $70.12 \pm 0.09 \mathrm{~b}$ \\
\hline
\end{tabular}

Value are means \pm standard errors. Means with the same letter within each column are not significantly different at $p<0.05$.

\subsection{Relative conductivity of blade}

All concentration treatments were improved the content in relative conductivity of blade in $P$. davidiana seedlings (Fig. 1). There were significant differences between the treatment with different concentration of chitosan and the control. The content in relative conductivity of blade in $P$. davidiana seedlings increased by $7.07 \%, 7.45 \%, 7.89 \%$ and $7.37 \%$ at $1 \mathrm{~g} / \mathrm{L}, 2 \mathrm{~g} / \mathrm{L}, 4$ $\mathrm{g} / \mathrm{L}$ and $6 \mathrm{~g} / \mathrm{L}$ compared with the control, respectively.

\subsection{Soil conductivity}

All concentration treatments were reduced the content in Soil conductivity (Fig. 2). Except for treatment of $1 \mathrm{~g} / \mathrm{L}$, there were significant differences between the other concentration treatments and the control. The content in soil conductivity decreased by $11.97 \%, 14.75 \%$ and $16.96 \%$ at $2 \mathrm{~g} / \mathrm{L}, 4 \mathrm{~g} / \mathrm{L}$ and $6 \mathrm{~g} / \mathrm{L}$ compared with the control, respectively. 


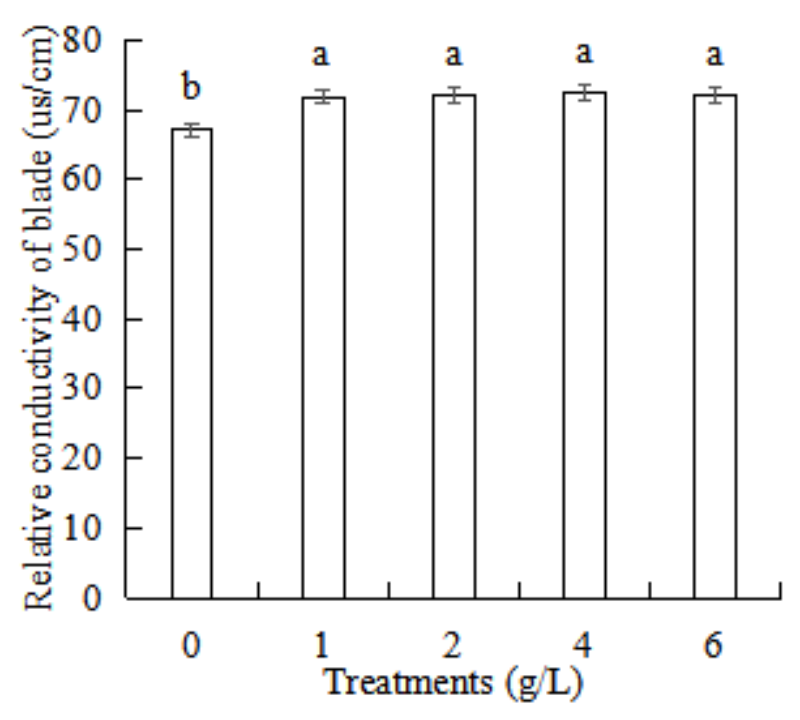

Figure 1. Relative conductivity of blade. Different lowercase letters indicate significant differences based on one-way analysis of variance in SPSS 18.0 followed by the least significant difference test $(p<0.05)$.

\section{Conclusions}

According to the experiment, all concentration treatments were reduced the soluble sugar content in root and stem of $P$. davidiana seedlings compared with the control and the concentration treatment of $1 \mathrm{~g} / \mathrm{L}$ and 2 $\mathrm{g} / \mathrm{L}$ was at a higher level. On the contrary, all concentration treatments were improved the soluble sugar content in leaves and shoot of $P$. davidiana seedlings compared with the control and the concentration treatment of $2 \mathrm{~g} / \mathrm{L}$ and $4 \mathrm{~g} / \mathrm{L}$ was at a higher level. All concentration treatments were improved the content in relative conductivity of blade in $P$. davidiana seedlings and the concentration treatment of 4 $\mathrm{g} / \mathrm{L}$ was at a higher level. On the contrary, all concentration treatments were reduced the content in soil conductivity and the concentration treatment of $1 \mathrm{~g} / \mathrm{L}$ was at a higher level. Therefore, the chitosan solutions concentration of $2 \mathrm{~g} / \mathrm{L}$ and $4 \mathrm{~g} / \mathrm{L}$ concentration was beneficial to soluble sugar content in $P$. davidiana seedlings. On the contrary, high concentration of chitosan solutions was not good for soluble sugar content.

\section{Acknowledgments}

This work was financially supported by the National Key Research and Development Plan of China (2018YFD0201400).

\section{References}

1. Chai, H.P., Zhang, W.Q., Jin, X.R. (1999) New trends in the development and research of chitin /chitosan. Chem. Bull., 7: 8-11.

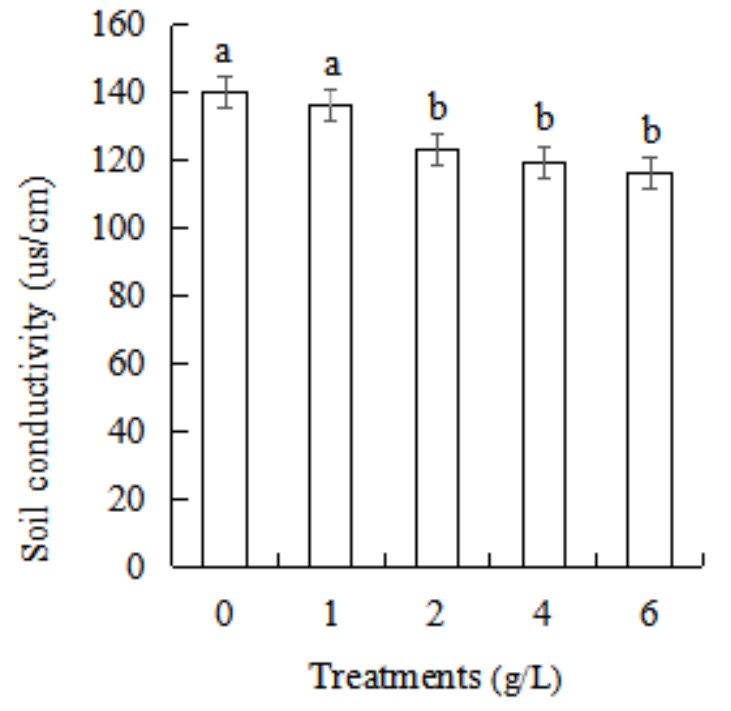

Figure 2. Soil conductivity. Different lowercase letters indicate significant differences based on one-way analysis of variance in SPSS 18.0 followed by the least significant difference test $(p<0.05)$.

2. Chen, J., Gao, G.Z., Zhao, L., Xu, L.S., Zhang, X.T., Xue, W. (2015) Effects of wheat seed soaking with chitosan on protective enzymetic activities in germination stage under drought stress, Gen. App. Bio., 34: 2251-2254.

3. Hang, Y.J., Tao, B. (2012) Effects of chitosan on the seedlings growth and the physiochemical activity of maize. J. Mai. Sci., 20: 73-76.

4. Xu, W.H., Xu F.F., Yu, X.F. (2010) Effects of chitosan on salt resistance of soybean seedlings under saly stress. Hubei Agric. Sci., 49: 1859-1861.

5. Wang, G.W., Han, X.D. (2010) Research advance on effects of chitosan on seed germination and seedling growth. North. Hortic., 12: 215-218.

6. Wang, C.W., Zhu, Q.Z., Ma, X.G. Zhou, H., Hao, Y.L. (2009) Effect of chitosan on radish seed germination and seedling physiological and biochemical characteris. North. Hortic., 6: 61-62.

7. Yu, M.G., Yang, H.Q., Liu, G.F., Zhang, J. (2003) Effects of chitosan on germination and growth of cucumber seeds. J. Changjiang. Veg., 3: 42-43.

8. Sheng,W., Zhang, X.M., Xue, J.P. (2007) Effect of chitosan on seeds germination and seedling physiological property of wheat. J. Biol., 24: 51-53.

9. Bao, S.D. (2000) Agrochemical soil analysis. China Agriculture Press, Beijing.

10. Hao, Z.B., Cang, J., Xu, Z. (2004) Plant physiology experiment. The Polytechnic University of Harbin Press, Harbin, China. 